\title{
Research on Coupling and Coordinating Development of Big Data Industry and Ecological Civilization in Guizhou
}

\author{
Xia Feng ${ }^{1,2,3}$, Mu Zhang ${ }^{1}$ \\ Guizhou University of Finance and Economics 1. College of Big Data Application and Economics; 2. Guizhou Institute of Innovation and \\ Venture Capital; 3. Guizhou Institute of Urban Economy and Development \\ Guiyang, China \\ rim_007@163.com

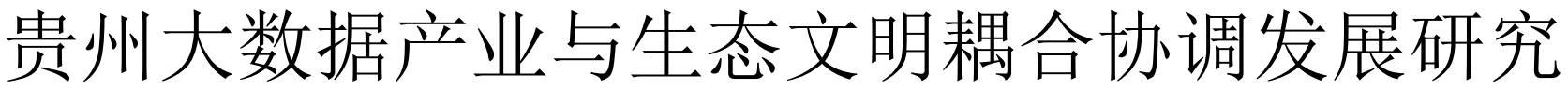 \\ 冯霞 $1,2,3$, 张目 1 \\ 贵州财经大学 1. 大数据应用与经济学院；2. 贵州科技创新创业投资研究院；3. 贵州城镇经济与发展研究院 \\ 贵阳 550025，中国 \\ rim 007@163.com
}

\begin{abstract}
In order to promote the coordinated development of Guizhou's big data industry and the construction of ecological civilization, this paper combines qualitative analysis with quantitative analysis. First, it creatively introduces the search engine data-Baidu index into the evaluation system, and establishes a large data industry water including three first-level indicators: industrial scale, infrastructure and Baidu index. The level rating index system and the level evaluation index system of ecological civilization construction including four first-level indicators of ecological economy, ecological environment, ecological livability and ecological culture. Then, using the panel data of nine cities in Guizhou Province from 2013 to 2017, the coupling and coordination model of large data industry system and ecological civilization construction system is constructed. According to the grey relational projection value calculated, the differences of the development level of big data industry and the level of ecological civilization construction in each prefecture and city are compared and analyzed, and then the corresponding measures are put forward according to the regional differences. Finally, nine prefectures in Guizhou are calculated by using the coupling coordination model. The change and development trend of coupling coordination degree between big data industry and ecological civilization construction in five years in the city of Guizhou are analyzed quantitatively. The development situation of coupling between big data industry system and ecological civilization construction system in Guizhou prefecture-level cities from 2013 to 2017 is analyzed, and relevant policy suggestions are put forward to further promote the construction of big data industry and ecological civilization in Guizhou. Deep and coordinated development.
\end{abstract}

Keywords-Search Engine Data; Large Data Industry Level Evaluation; Ecological Civilization Construction Level Evaluation; Coupling and Coordination

摘要一为促进贵州大数据产业与生态文明建设协调发展, 本文以定性分析与定量分析相结合的方法, 首先创造性地将 搜索引擎数据-百度指数引入到评价体系中, 建立了包含产业 规模、基础设施、百度指数三个一级指标的大数据产业水平 评级指标体系和包含生态经济、生态环境、生态宜居和生态
文化四个一级指标的生态文明建设水平评价指标体系; 然 后, 采用 2013-2017 年贵州省九个地州市的面板数据, 构建 出大数据产业系统与生态文明建设系统的耦合协调模型, 并 运用熵权法赋予各指标权重, 根据计算所得的灰色关联投影 值, 比较分析各个地州市的大数据产业发展水平和生态文明 建设水平的差异, 进而针对地区的差异提出针对性的措施; 最后, 运用耦合协调模型计算贵州九个地州市五年内的大数 据产业和生态文明建设的耦合协调度变化情况与发展趋势, 定量分析贵州地级市 2013-2017 年大数据产业系统与生态文 明建设系统耦合的发展情况, 并提出相关政策建议, 进一步 促进贵州大数据产业与生态文明建设的深度协调发展。

关键词一搜索引擎数据, 大数据产业水平评级, 生态文明 建设水平评价, 耦合协调

\section{I. 引言}

自改革开放以来, 中国在经济建设上取得了举世瞩 目的成就, 尤其是近几年来, 我国国内经济发展水平快 速, 人民生活水平显著提高。但是纵观近代中国经济发 展过程, 经济的高增长伴随着自然环境的恶化、资源减 少, 已严重的影响到生态文明。因此, 党的十八大将生 态文明建设纳入到中国特色社会主义的 “五位一体”布 局，同时提出 “创新、协调、绿色、共享、开放” 的发 展理念，对生态文明建设提出更高要求。

数据是国家基础性战略资源, 是 21 世纪的 “钻石 矿”。我国高度重视大数据在经济社会发展中的作用, 为了全面推进大数据发展, 加快建设数据强国, 党的十 八大提出 “实施国家大数据战略”。大数据作为新兴技 术产业不在受时间和空间的限制, 其广泛的应用价值在 各个产业逐渐显现出来, 从而转变为一种新型的产业发 展模式, 利用大数据技术改变产业结构促进产业升级, 这为我国的生态文明建设提供了一条新型路径。2016 年 3 月国家发布的《生态环境大数据建设总体方案》中明 确指出高度重视大数据在推进生态文明建设中的地位和 作用, 推进全国生态环境监测数据联网共享, 开展生态 
环境大数据分析。由此可见，大数据产业与生态文明建 设通过整合，可以实现优势互补、推动我国大数据产业 和生态文明建设协调发展，对于建设 “美丽中国” 具有 重要意义。

从以往研究来看, 国外在大数据概念、价值、大数 据产业等方面的研究较多, 国内的学者在大数据产业概 念、类型、现状等方面进行阐述，其中我国最早大数据 产业定义是孙庆君（1998） [1]提出的, 他认为广义数据 产业包含信息工业的全部，狭义数据产业是指信息加工 业和信息服务业。之后, 国内学术界基于不同的学科和 研究视角对大数据产业进行了各个层面的分析。迪莉娅

(2014) [2]从大数据产业类型、特点和国外大数据产业 发展环境, 重点分析我国大数据产业现状; 茶洪旺和郑 婷婷 (2018) ${ }^{[3]}$ 从产业规模、产业形态等 6 个方面分析 我国大数据产业发展状况, 并进一步从安全等 7 个方面 说明我国大数据产业面临问题。生态文明的研究也较为 丰富, 国外主要从生态学角度开始研究, 德国一名生物 家 E.H.Haeckd (2003) [4]首次提出了 “生态学” 的概 念; 著名专家 A.G.Tansley（2010） [5]在生态学的基础上 进一步对 “生态系统” 这一概念进行了研究; 权威学者 EJP.Odum（2014） [6]通过对生态文明领域的进一步探 索, 在原来基础上对生态学的内容进行了拓展, 进一步 丰富了生态文明的内涵。而国内的谷树忠等人（2013） [7]分别从人与自然的关系、生态文明与现代文明的关 系、生态文明与时代发展的关系三个方面阐释了生态文 明建设的内涵, 并对生态文明建设路径选择、设计和推 进机制提出具体建议。王灿发、王树义（2014） ${ }^{[8][9]}$ 分 别从法律层面构建生态文明法律保证体系、从司法改革 角度切入生态文明建设与环境保护的关系。

虽然国内外对于大数据产业和生态文明的研究都相 对成熟，但是只有少数专家学者将大数据产业与生态文 明结合起来分析。文贤庆 (2015) [10]通过将大数据思维 和生态文明思维融合说明了二者无论在可能性上还是必 然性上都能够高度的相容; 王陆潇等人（2017） [11]应用 大数据来构建生态文明建设新模式, 目的想要形成生态 环境大数据初步框架。其中有部分专家学者将科技和生 态文明联系在一起研究, 刘明、董仁才（2012） [12]主张 以现代的新技术来引领生态文明建设; 陈钦萍、陈忠等 人（2015）[13]采用拓展的 C-D 生产函数模型得出科技投 入对生态文明建设有显著的正向作用。因此为了拓展两 者之间的互动关系研究, 本文通过采用直觉模糊层次分 析法对贵州省大数据产业发展水平和生态文明建设水平 进行评价, 将大数据产业和生态文明建设视为两个子系 统, 以耦合协调度模型开展两者之间关系的研究, 探讨 两者之间发展现状和规律，并提出可行的对策和建议。

\section{II. 大数据产业与生态文明的相互作用机理}

由于在构建大数据平台形成大数据产业过程中会对 生态环境造成影响, 主要包括产业规模和基础设施等因 素为环境带来的压力, 而生态环境在承受压力的情况 下，会反应到生态文明当前的建设状况，包括森林面 积、空气质量、水源地水质、污染物排放等方面。此 时, 为治理生态环境、防止环境进一步恶化、预防生态 危机，决策者进而采取一系列的措施，主要包括政策手 段、经济手段、法律手段、技术手段等方面。大数据产 业与生态文明建设之间存在相互促进相互制约的关系，
一方面, 大数据产业可以通过新型的信息化技术，快捷 全面的掌握生态文明建设状况信息, 还可以对环境问题 进行实况检测, 为制定科学合理的环境政策提供导向, 但是大数据在建造过程中产生一定程度的污染又会破坏 生态文明; 另一方面, 良好的生态文明建设是确保大数 据产业建立的基础。

\section{III. 大数据产业与生态文明综合评价体系构建}

III. 1 数据来源和指标体系构建

本章研究选取 2013 至 2017 年贵州省 9 个地州市的 数据。数据来源于《中国区域经济统计年鉴》、《贵州 省统计年鉴》、九个地州市的统计年鉴、地州市水资源 公报、环境公报和国民经济发展公报。

在对大数据产业和生态文明全面分析及发展状况全 面了解的基础上, 为了科学合理的构建指标体系、综合 全面的反应现实情况, 应遵循可操作性、可代表性、科 学性、严谨性等基本原则。在遵循指标体系构建基本原 则的前提下，本文借鉴林震，双志敏（2014） [14]等研 究, 从产业规模和基础设施两个方面构建有 13 个二级指 标的大数据产业测度的指标体系; 从生态经济、生态环 境、生态宜居和生态文化四个方面构建有 24 个二级指标 的生态文明测度的指标体系。最终构建大数据产业一生 态文明系统耦合协调发展评价体系, 各级指标如表 1 所 示。

表 1 大数据产业一生态文明系统耦合协调发展评价体系

\begin{tabular}{|c|c|c|}
\hline 目标层 & 一级指标 & 二级指标 \\
\hline \multirow{4}{*}{$\begin{array}{l}\text { 生态文明 } \\
\text { 建设 }\end{array}$} & $\begin{array}{l}\text { 生态经济 } \\
A_{1}\end{array}$ & $\begin{array}{c}\text { 人均生产总值（元） } \mathrm{A}_{11} \text {; 第三产业 } \\
\text { 增加值占 } \mathrm{GDP} \text { 的比重增长率 (\%) } \mathrm{A}_{12} \text {; 人 } \\
\text { 均一般公共预算收入增速 (\%) } \mathrm{A}_{13} \text {; 单位 } \\
\mathrm{GDP} \text { 能耗 (吨标准煤/万元) } \mathrm{A}_{14} \text {; 单位 } \mathrm{GDP} \\
\text { 电耗 (千瓦时/万元) } \mathrm{A}_{15} \text {; 一般公共预算 } \\
\text { 支出一节能环保 (亿元) } \mathrm{A}_{16}\end{array}$ \\
\hline & $\begin{array}{l}\text { 生态环境 } \\
A_{2}\end{array}$ & $\begin{array}{c}\text { 森林覆盖率 }(\%) \mathrm{A}_{21} \text {; 城区环境空气 } \\
\text { 质量优良率 }(\%) \mathrm{A}_{22} \text {; 县级以上集中式饮 } \\
\text { 用水源地水质达标率（\%) } \mathrm{A}_{23} \text {; 农用化肥 } \\
\text { 施用量增长率 }(\%) \mathrm{A}_{24} \text {; 工业固体废物综 } \\
\text { 合利用率 (\%) } \mathrm{A}_{25} \text { ，二氧化硫排放总量 } \\
\text { (万吨） } \mathrm{A}_{26}\end{array}$ \\
\hline & $\begin{array}{l}\text { 生态宜居 } \\
A_{3}\end{array}$ & $\begin{array}{c}\text { 人均公园绿地面积 (平方米/人) } \\
\mathrm{A}_{31} ; \text { 城市生活垃圾无害化处理率 }(\%) \\
\mathrm{A}_{32} ; \text { 平均气温 }(\text { 。 C }) \mathrm{A}_{33} ; \text { 年降水量 } \\
(\mathrm{mm}) \mathrm{A}_{31} ; \text { 人均公路里程 (千米/万人) } \\
\mathrm{A}_{35} ; \text { 城区人均住房面积 } \mathrm{A}_{36}\end{array}$ \\
\hline & $\begin{array}{l}\text { 生态文化 } \\
A_{4}\end{array}$ & $\begin{array}{l}\text { 一般公共预算支出-教育服务 (亿 } \\
\text { 元) } \mathrm{A}_{41} \text {; 一般公共预算支出-文化体育与 } \\
\text { 传媒 (亿元) } \mathrm{A}_{42} \text {; 高等教育在校学生数 } \\
\text { (人) } \mathrm{A}_{43} \text {; 普通中学在校学生 (人) } \mathrm{A}_{44} \text {; } \\
\text { 百度指数 pc 端的搜索量 (次) } \mathrm{A}_{45} \text {; 百度 } \\
\text { 指数移动端的搜索量 (次) } \mathrm{A}_{46}\end{array}$ \\
\hline \multirow{3}{*}{ 大数据产业 } & $\begin{array}{l}\text { 产业规模 } \\
\text { B1 }\end{array}$ & $\begin{array}{l}\text { 规模以上企业数 (个) } \mathrm{B}_{11} \text {; 企业全 } \\
\text { 部从业人员年平均人数 (人) } \mathrm{B}_{12} \text { ，工业总 } \\
\text { 产值 (亿元) } \mathrm{B}_{13} \text { ；业增加值（亿元） } \\
\mathrm{B}_{14} \text {; 资产总计 (亿元) } \mathrm{B} 15 \text {; 主营业务收 } \\
\lambda \text { (亿元) } \mathrm{B}_{16} \text {; 利润总额 (亿元) } \mathrm{B}_{17} ; \text { 固 } \\
\text { 定资产本年累计完成投资 (亿元) } \mathrm{B}_{18}\end{array}$ \\
\hline & $\begin{array}{l}\text { 基础设施 } \\
\text { B2 }\end{array}$ & $\begin{array}{c}\text { 年末移动电话用户（万户） } \mathrm{B}_{21} \text {; 互 } \\
\text { 联网宽带接入用户 (万户) } \mathrm{B}_{22} \text {; 年末固定 } \\
\text { 电话用户数 (万户) } \mathrm{B}_{23} \text {; }\end{array}$ \\
\hline & $\begin{array}{l}\text { 百度指数 } \\
\text { B3 }\end{array}$ & $\begin{array}{c}\mathrm{PC} \text { 端搜索指数 (频次) } \mathrm{B}_{31} \text {; 移动端 } \\
\text { 搜素指数 (频次) } \mathrm{B}_{32}\end{array}$ \\
\hline
\end{tabular}


III.2 基于 TOPSIS 的大数据产业综合评价方法

基于犹豫模糊语言的 TOPSIS 方法的思想, 建立犹 豫模糊多属性决策方法, 用以测度贵州大数据产业发展 水平。为保持客观性, 采用熵权法计算大数据产业发展 水平评价体系的指标权重。

III.3 基于灰色关联投影的生态文明综合评价方法

运用灰色关联投影法的多属性决策原理, 计算出决 策方案在最优方案上的投影值为灰色关联投影值, 即为 生态文明建设水平的综合评价值。

\section{III.4 耦合度模型}

耦合起初是物理学中的概念, 指两个或者两个以上 的子系统之间通过各种相互作用而彼此相互影响以达到 协同的一种现象。随着耦合理论的发展, 其逐渐被应用 到社会科学领域的研究中, 用以研究社会现象间关联发 展的内在相互作用机制。耦合度是衡量子系统间相互关 联程度的测量指标, 耦合度越高, 则子系统间关联性越 大，且向着有序方向发展；耦合度越低，则子系统间关 联性越小，且向着无序方向发展。借鉴物理学中的容量 耦合概念, 得到多个要素之间相互作用的耦合度模型, 即:

$C=\mathrm{n}\left\{f\left(u_{1}\right) \times f\left(u_{2}\right) \times \ldots \times f\left(u_{n}\right) /\left(f\left(u_{1}\right) \times f\left(u_{2}\right) \times \ldots \times f\left(u_{n}\right)\right)^{n}\right\}^{\frac{1}{n}}$

其中 $\mathrm{n}$ 为耦合的系统个数, 耦合度 $\mathrm{C}$, 的取值区间 为 $[0,1]$, 当 $\mathrm{Cn}=0$ 时, 耦合度最小, 两者达到不协调 的极端状态; $\mathrm{Cn}$ 越大, 两者越协调: 当合度 $\mathrm{C}=1$ 时, 耦合度最大, 系统之间或系统内部要素之间达到良性共 振, 两者协调达到最佳状态。由于本研究只涉及到大数 据产业与生态文明两个子系统, 所以构建的耦合度模型 如下:

$$
C=\left\{\frac{U_{1} \times U_{2}}{U_{1}+U_{2}}\right\}^{1 / 2}
$$

如上式所示, 大数据产业与生态文明的耦合度值 C $\in[0,1], C$ 是指大数据产业与生态文明的耦合度,

U1、U2 分别为大数据产业子系统和生态文明子系统的 综合得分。当 $\mathrm{C}=0$ 时, 耦合度极低, 两个子系统之间处 于无序状态, 两者之间基本不存在相互作用; 当 $\mathrm{C}=1$ 时, 耦合度极高, 两个子系统之间达到良性共振。参照文献 我们将耦合程度划分为四个层次: $\mathrm{C}=0$, 无耦合; $0<\mathrm{C}$ $\leqq 0.3$ 表示系统处于低水平耦合, 处于起步时期; $0.3<\mathrm{C}$ $\leqq 0.8$ 表示系统处于中水平耦合, 处于发展时期 $; 0.8<\mathrm{C}$ $\leqq 1$ 表示系统处于高水平耦合, 处于成熟时期。

III. 5 耦合协调模型
协调是指系统间在发展过程中所表现出的一种彼此 和谐一致、相互促进的关联关系。耦合协调度是系统间 相互影响、相互作用过程中协调共赢程度的定量测量, 能够体现系统或要素间耦合由无序向有序转变的趋势, 能够体现其间协调发展质量的优劣程度。本文引入耦合 协调理论, 以大数据产业与生态文明作为两个个耦合协 调子系统, 将两者间相互作用关系定义为耦合协调关 系, 从耦合协调发展的视角, 分析两者者间相互影响、 相互促进和谐发展的共生作用机制, 测量两者间的耦合 协调度。大数据产业与生态文明交互耦合的协调程度, 如下式所示:

$$
\left\{\begin{array}{c}
D=\sqrt{C * M} \\
M=\alpha * U_{1}+\beta * U_{2}
\end{array}\right.
$$

其中, $\mathrm{D}$ 大数据产业与生态文明耦合协调度, 取值 $\mathrm{D} \in[0,1] ; \mathrm{C}$ 为耦合度; $\mathrm{M}$ 为大数据产业与生态文明耦 合协调指数, 反应两者的整体协同效应。 $\alpha$ 和 $\beta$ 皆为待 定参数 $(\alpha+\beta=1)$ 。

在实际应用过程中，根据耦合协调度的大小，借鉴 白彩全（2014）[15]等人研究将耦合协调度划分为十个层 次, 并对金融发展与生态扶贫之间的耦合协调度等级进 行细分, 共划分 10 个一级等级, 30 个二级等级, 如表 2 所示，耦合协调类型划分见表 3。

\begin{tabular}{|c|c|}
\hline 第一层次类型 & 划分标准 \\
\hline
\end{tabular}

表 2 两个子系统之间耦合协调度等级划分

协调发展类

$[0.80,0.89]$

优质协调

$[0.70,0.79]$

良好协调

$[0.60,0.69]$

中级协调

$[0.50,0.59]$

初级协调

过渡发展类

$[0.40,0.49]$

勉强协调

$[0.30,0.39]$

濒临失调

$[0.20,0.29]$

轻度失调

失调衰退类

$[0.10,0.19]$

中度失调

严重失调

$[0.00,0.09]$

极度失调

表 3 耦合协调类型划分

D 类型 U1 和 $\mathrm{U} 2$ 关系

发展类型

失调发展类 $\quad 0-0.09 \quad$ 极度失调发展类

$\mathrm{U} 1>\mathrm{U} 2$

极度失调生态文明建设损益型

$\mathrm{U} 1=\mathrm{U} 2$

极度失调共损型

$\mathrm{U} 1<\mathrm{U} 2$

极度失调大数据产业损益型 
0.10-0.19严重失调发展类

中度失调发展类

轻度失调发展类

$0.30-0.39$

$01>02$

$\mathrm{U} 1=\mathrm{U} 2$

$\mathrm{U} 1<\mathrm{U} 2$

0. 40-0.49濒临失调发展类

$0.50-0.59$

勉强协调发展类

$0.60-0.69$

初级协调发展类

$0.70-0.79$

中级协调发展类

良好协调发展类

$0.80-0.89$

优质协调发展类
$\mathrm{U} 1>\mathrm{U} 2$

$\mathrm{U} 1=\mathrm{U} 2$

$\mathrm{U} 1<\mathrm{U} 2$

$\mathrm{U} 1>\mathrm{U} 2$

$\mathrm{U} 1=\mathrm{U} 2$

$\mathrm{U} 1<\mathrm{U} 2$

$\mathrm{U} 1>\mathrm{U} 2$

$\mathrm{U} 1=\mathrm{U} 2$

$\mathrm{U} 1<\mathrm{U} 2$

$\mathrm{U} 1>\mathrm{U} 2$

$\mathrm{U} 1=\mathrm{U} 2$

$\mathrm{U} 1<\mathrm{U} 2$

$\mathrm{U} 1>\mathrm{U} 2$

$\mathrm{U} 1=\mathrm{U} 2$

$\mathrm{U} 1<\mathrm{U} 2$

$\mathrm{U} 1>\mathrm{U} 2$

$\mathrm{U} 1=\mathrm{U} 2$

$\mathrm{U} 1<\mathrm{U} 2$
严重失调生态文明建设损益型

严重失调共损型

严重失调大数据产业损益型

中度失调生态文明建设损益型

中度失调共损型

中度失调大数据产业损益型

轻度失调生态文明建设损益型

轻度失调共损型

轻度失调大数据产业损益型

濒临失调生态文明建设损益型

濒临失调共损型

濒临失调大数据产业损益型

勉强协调生态文明建设滞后性

勉强协调同步型

勉强协调大数据产业滞后性

初级协调生态文明建设滞后性

初级协调同步型

初级协调大数据产业滞后性

中级协调生态文明建设滞后性

中级协调同步型

中级协调大数据产业滞后性

良好协调生态文明建设滞后性

良好协调同步型

良好协调大数据产业滞后性

优质协调生态文明建设滞后性

优质协调同步型

优质协调大数据产业滞后性
IV. 实证结果分析

本章研究运用基于犹豫模糊语言的 TOPSIS 方法和 灰色关联投影法测度大数据产业和生态文明的综合发展 水平。同时运用耦合度模型和耦合协调度模型计算各地 级市和自治州大数据产业和生态文明各个年份的耦合协 调度（D2013 D2017），再将其平均得各地级市和自治 州的整体耦合协调度 $\mathrm{D}$, 根据耦合协调度等级及其划分 标准得贵州省地级市和自治州大数据产业和生态文明的
耦合协调发展状况。在研究两个子系统的耦合协调过程 中, 大数据产业中可为解决生态文明提供新的渠道, 而 生态文明的建设又为大数据发展提供了良好的环境, 所 以本文的耦合分析认为大数据产业和生态文明同等重 要, 并结合相关学者的文献, 将待定参数确立为 $\alpha=\beta$ $=1 / 2$ 即 $M=(U 1+U 2) / 2$ 。贵州省 9 个地州市两个子系统的 耦合度和耦合协调度计算结果如表 4 所示。大数据产业 与生态文明耦合协调程度的时间变化趋势如图 1 所示。 
表 4 大数据产业与生态文明耦合协调发展状况

\begin{tabular}{clllllcccc}
\hline & D2013 & D2014 & D2015 & D2016 & D2017 & U1 & U2 & D & 耦合协调类型 \\
\hline 贵阳市 & 0.5458 & 0.5881 & 0.5761 & 0.5347 & 0.7056 & 1 & 0.5184 & 0.5900 & 勉强协调发展 \\
遵义市 & 0.5499 & 0.4733 & 0.4931 & 0.5143 & 0.6426 & 0.6968 & 0.5411 & 0.5347 & 勉强协调发展 \\
黔东南 & 0.4217 & 0.3828 & 0.4009 & 0.4028 & 0.4429 & 0.1583 & 0.7333 & 0.4102 & 濒临失调发展 \\
黔南州 & 0.4371 & 0.4308 & 0.3958 & 0.3838 & 0.3896 & 0.1447 & 0.7945 & 0.4074 & 濒临失调发展 \\
黔西南 & 0.3630 & 0.3976 & 0.3976 & 0.4364 & 0.4228 & 0.1174 & 0.9187 & 0.4035 & 濒临失调发展 \\
铜仁市 & 0.4035 & 0.3820 & 0.3681 & 0.2746 & 0.4393 & 0.1451 & 0.5937 & 0.3735 & 轻度失调发展 \\
安顺市 & 0.3026 & 0.3372 & 0.3688 & 0.3457 & 0.3694 & 0.1317 & 0.4443 & 0.3448 & 轻度失调发展 \\
毕节市 & 0.2686 & 0.3378 & 0.3364 & 0.3605 & 0.3982 & 0.2089 & 0.2767 & 0.3403 & 轻度失调发展 \\
六盘水 & 0.3315 & 0.2424 & 0.2956 & 0.2824 & 0.2731 & 0.2158 & 0.1411 & 0.2850 & 中度失调发展 \\
\hline
\end{tabular}

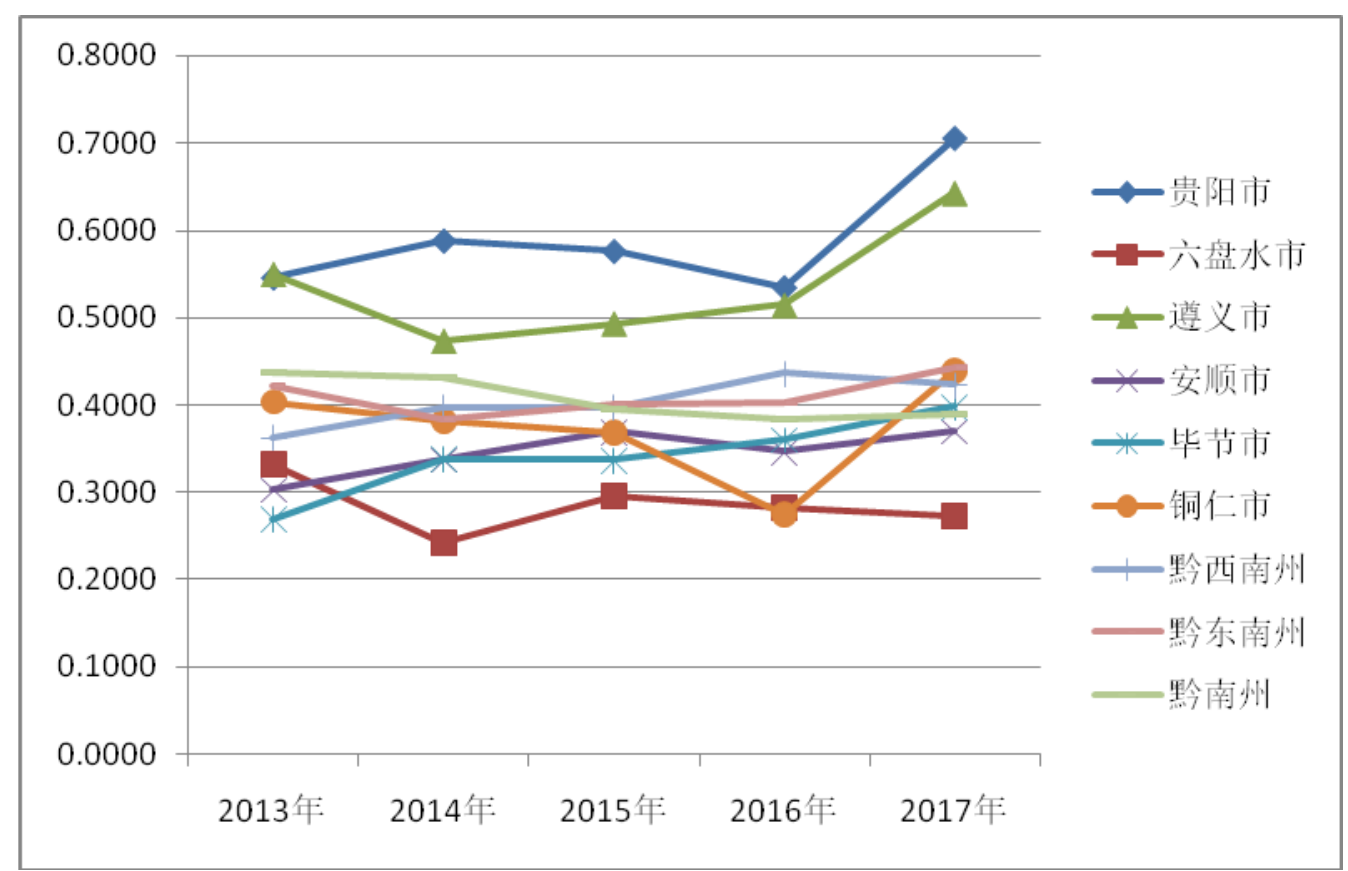

图 1 大数据产业与生态文明耦合协调程度的时间变化趋势

\section{V. 结论及政策建议}

根据 2013-2017 年贵州九个地级市两个子系统的指 标原始数据, 运用耦合度模型、耦合协调度模型, 对贵 州地级市大数据产业-生态文明建设耦合协调发展状况 进行实证分析, 得出以下结论:

（1）从总体上看, 耦合协调度普遍较低。耦合协 调类型总体属于勉强协调的有贵阳市和遵义市; 属于濒 临失衡的有黔东南州、黔西南州、黔南州; 属于轻度失 衡的有铜仁市、安顺市、毕节市; 六盘水市属于中度失 衡。其中, 生态文明建设滞后型的地区有贵阳市、遵义 市、六盘水市; 大数据产业发展滞后型的地区有黔南 州、安顺市、黔东南州、铜仁市、黔西南州、毕节市。

（2）从空间上看, 勉强协调类型、濒临失衡类型 主要集中在贵阳市、遵义市、黔南州等贵州中北部经济 发达地区以及西南部生态环境优良地区, 而轻度、中度 失衡类型主要分布于安顺市、六盘水市等贵州西部经济 欠发达地区。说明贵州经济发达地区大数据产业-生态 文明建设的协调发展程度明显高于经济欠发达地区。

（3）从时间上看, 耦合协调类型并非一成不变, 总体趋势是向更高的耦合协调类型转变。其中, 贵阳市 由 2013 年的勉强协调上升为 2017 年的初级协调; 2014 年毕节市的耦合协调度是最低, 属于中度失衡发展, 但
在随后几年内耦合协调度逐年递增, 至 2017 年已属于 轻度失衡发展; 铜仁市的大数据产业和生态文明耦合协 调状况波动较大, 从濒临失衡发展转向轻度失衡发展, 在 2017 年又恢复到濒临失衡发展水平。

根据上述研究结论, 结合有关部门文件精神, 提出 以下政策建议:

(1) 对于生态文明建设滞后型的地区, 应转变地 区经济增长方式、优化地区产业结构、提高地区资源利 用效率、加大地区科研经费投入, 促进经济发展和可持 续发展, 推动生态经济发展。加强地区生态建设、大力 发展地区循环经济、着力提高地区环境质量, 不断改善 生态环境及环境保护水平。提高森林覆盖率、建成区绿 化覆盖率和水域面积, 提高地区生态资源规模; 控制地 区人口密度、提高地区人均道路面积和地区人均住房面 积, 减轻地区人口拥挤现象, 提高生态宜居度。加强生 态文明建设宣传教育、大力发展文化产业、引导文化消 费, 提高城乡居民生态文明素养、文化产业发展水平及 公共文化服务水平。

(2) 对于大数据产业发展滞后型的地区, 应加快 培育和发展地区电子信息产业, 重点发展与大数据关系 密切的软件、集成电路、物联网、下一代互联网、云计 算等子产业, 为大数据产业发展提供产业基础。应充分 发挥地区生态优势、能源优势、区位优势、战略优势, 
采取政府引导、企业主体、市场化运作的模式，着力提 高大数据产业的要素投入，在财政扶持、金融支持、用 地保障、电力供给等方面加大扶持力度; 以大数据领域 研发和产业化项目为载体, 积极引进高端人才, 着力提 高大数据产业的产业规模和产业影响力。

\section{致谢}

本文获得国家自然科学基金地区项目（71861003）和 2017 年度第二批贵州省基础研究计划 (软科学类别) 项 目 “贵州大数据产业集聚效应及金融支持体系研究” （黔科合基础（2017）1516-1）资助。

\section{参考文献}

１］孙庆君.中国数据产业发展报告.经济与信息,1998 年, pp.44-49.

[2] 迪莉娅. 我国大数据产业发展研究. 科技进步与对策, 2014 年,vol.31,issue2,pp.56-60.

[3] 茶洪旺, 郑婷婷. 中国大数据产业发展研究. 中州学刊, 2018 年, issue4,pp.19-25.

[4] E.H.Haeckel. Characterizing and measuring sustainable development.Review of Environment and Resources ,2003,pp.559586.
[5] Tansley A G. THE PROBLEMS OF ECOLOGY.New Phytologist,2010,vol3, issue8,191-200.

[6] Odum E P. The strategy of ecosystem development.The Ecological Design and Planning Reader.Island Press Center for Resource Economics,2014,pp262-270.

[7] 谷树忠, 胡咏君, 周洪. 生态文明建设的科学内涵与基本路径. 资源 科学, 2013,vol35,issue1,pp2-13.

[8] 王灿发. 论生态文明建设法律保障体系的构建. 中国法 学, 2014,issue3,pp34-53.

[9] 王树义. 论生态文明建设与环境司法改革. 中国法 学, 2014,issue3,pp54-71.

[10] 文贤庆. 大数据技术及其在生态文明建设中的应用. 南京林业大学 学报 (人文社会科学版), 2015,vol15,issue1,pp9-19.

[11] 王陆潚, 刘晓, 罗庆俊. 探索用大数据推动生态文明建设新模式. 环 境保护, 2017,vol45, issue4,pp72-73.

[12] 刘明,董仁才.以现代科技文明引领城市生态文明建设.生态经 济,2012,issue2,pp181-184.

[13] 陈钦萍,陈忠,卓禁百,陈旭辉.科技投入对生态文明建设的贡献分 析 - - 基于拓展的 C-D 生产函数. 林业经 济,2015,vol37,issue12,pp97-101.

[14] 林震,双志敏.省会城市生态文明建设评价指标体系比较研究一 以贵阳市、杭州市和南京市为例. 北京航空航天大学学报(社会科 学版),2014,vol27,issue5,pp22-28.

[15] 白彩全,黄芽保,宋伟轩,何宜庆.省域金融集聚与生态效率耦合协 调发展研究[J].干旱区资源与环境,2014,vol28,issue9,pp1-7. 